\title{
The effect of electrochemical nitridation on the corrosion resistance of the passive films formed on the 2205 duplex stainless steel
}

\author{
Lv Jinlong ${ }^{\mathrm{a}, *}$, Huijin Jin ${ }^{\mathrm{b}, *}$, Liang Tongxiang ${ }^{\mathrm{a}}$ \\ a Institute of Nuclear and New Energy Technology, Tsinghua University, Zhongguancun Street, Haidian District, Beijing 100084, China \\ ${ }^{\mathrm{b}}$ State Key Laboratory of Nonlinear Mechanics, Institute of Mechanics, Chinese Academy of Sciences, Beijing 100190, China
}

\section{A R T I C L E I N F O}

\section{Article history:}

Received 31 July 2019

Received in revised form 6 September 2019

Accepted 7 September 2019

Available online 7 September 2019

\section{Keywords:}

Electrochemical nitridation

Nitridation

Corrosion

Passive film

Mott-Schottky

\begin{abstract}
A B S T R A C T
The effects of electrochemical nitridation on the corrosion resistance of the 2205 duplex stainless steel were investigated. It was found that increased nitrogen content in the 2205 duplex stainless steel affected donor and acceptor concentration distribution in the passive films on the surface of the 2205 duplex stainless steel. Moreover, the total donor and acceptor concentration in passive films decreased with the increasing of nitrogen content. The electrochemically nitridation facilitated to induce compact passive film and thus improved significantly the corrosion resistance of the 2205 duplex stainless steel in borate buffer solution.
\end{abstract}

(c) 2019 Elsevier B.V. All rights reserved.

\section{Introduction}

Nitrogen and nickel are both austenite-stabilizing elements. However, nickel is expensive and could cause an allergic reaction to human skin [1]. Therefore, the nitrogen may be used to replace the nickel. High nitrogen austenitic stainless steels have been developed as structural materials for replacing commercial austenitic stainless steels [2]. López et al. [3] found that the nitrogen addition improved the corrosion resistance of austenitic and martensitic stainless steels due to enhanced repassivation ability by solid solution nitrogen. The nitrogen alloying decreased the donor densities in passive films formed on 316LN stainless steel in $\mathrm{Na}_{2} \mathrm{SO}_{4}$ and $\mathrm{NaCl}$ aqueous solutions and thus inhibited metastable corrosion pits [4]. It was found that the passive films on high nitrogen nickel-free stainless steel was thicker and more protective due to the higher nitrogen content in different simulated body fluids [5], thus, donor density in passive films decreased by nitrogen addition. The Mott-Schottky measurements demonstrated that the donor and acceptor densities in passive films decreased with the increasing of nitrogen content for 316LN stainless steels in sodium chloride and borate buffer solutions [6]. Traditional nitriding temperature of the stainless steels is relatively high [7]. The nitriding treatment performed at lower temperature effectively inhibited

\footnotetext{
* Corresponding authors.

E-mail addresses: ljltsinghua@126.com (L. Jinlong), jinhuijin863@163.com
} (H. Jin). large $\mathrm{CrN}$ precipitation and facilitated to form nitrogen supersaturated austenitic metastable phase [8]. The duplex stainless steels have become a very good option for wide applications in different fields due to their high strength and excellent toughness properties as well as their high corrosion resistance. Nitrogen has a higher solubility in austenitic phase than in ferritic phase [9]. Therefore, firstly, the effect of electrochemical nitridation time on the surface nitrogen content of the 2205 duplex stainless steel is investigated. Then, the effects of electrochemical nitridation time on the passivation characteristic and the corrosion resistance of the 2205 duplex stainless steel are further evaluated in this study.

\section{Experimental}

The composition ( $\mathrm{wt} \%$ ) of the investigated 2205 duplex stainless steel is as follows: C 0.05, Mn 1.05, P 0.022, S 0.0008, Si 0.75, Cr 21.85, Ni 5.36, Mo 3.18, Cu 0.18, V 0.13, W 0.054, Ti 0.015, N 0.155 , and Fe balance. All the electrochemical experiments were conducted on with the $\mathrm{CHI} 660 \mathrm{E}$ electrochemical workstation. The counter, working and reference electrode were a large platinum foil, duplex stainless steel and saturated calomel electrode (SCE), respectively. The electrochemical nitridation process for the 2205 duplex stainless steel was conducted in a mixed solution of $0.1 \mathrm{M} \mathrm{HNO}_{3}+0.5 \mathrm{M} \mathrm{KNO}_{3}$ at $25{ }^{\circ} \mathrm{C}$. Firstly, the duplex stainless steel substrates were stabilized at open circuit potential (OCP) for $5 \mathrm{~min}$, and then the cathodic potential of $-0.7 \mathrm{~V}_{\mathrm{SCE}}$ was applied for $10 \mathrm{~h}, 20 \mathrm{~h}$ and $30 \mathrm{~h}$, respectively. Finally, electrochemically 
nitrided specimens were washed and rinsed with deionized water and acetone, respectively. The compositions and chemical state of the electrochemically nitrided 2205 duplex stainless steel and the surface passive films formed on electrochemically nitrided 2205 duplex stainless steel were analyzed by the X-ray photoelectron spectroscopy (XPS, PHI Quantera SXM, ULVAC-PHI, INC). The obtained XPS data were analyzed by the XPSPeak4.1 software. The corrosion resistance of the passive films formed on the surface of the 2205 duplex stainless steel was evaluated in borate buffer solution ( $\left.0.05 \mathrm{M} \mathrm{H}_{3} \mathrm{BO}_{3}+0.075 \mathrm{M} \mathrm{Na}_{2} \mathrm{~B}_{40} \mathrm{O}_{7} \cdot 10 \mathrm{H}_{2} \mathrm{O}\right)$. The MottSchottky measurements were performed for investigating the semiconductor characteristics of the passive film and its charge carrier densities. All the samples were passivated at $0.6 \mathrm{~V}_{\mathrm{SCE}}$ for $2 \mathrm{~h}$, then the Mott-Schottky and electrochemical impedance spectroscopy (EIS) measurements were carried out at room temperature.

\section{Results and discussion}

EBSD-reconstructed orientation and phase maps of solid solution sample are shown in Fig. 1a and b, respectively. The colored maps can distinguish between the austenitic and ferritic phases in Fig. 1b. The average grain size is about $30 \mu \mathrm{m}$ for the $\gamma$ phase and $23 \mu \mathrm{m}$ for the $\alpha$ phase. The $\gamma$ and $\alpha$ phases are strain free in solid solution condition. It is worth noting that $\gamma$ phase completely surrounds the grains of $\alpha$ phase. This complete and incomplete wetting of grain boundaries due to second solid phase could also affect subsequent electrochemical nitridation [10]. The surface XPS N1s and Mo3 $\mathrm{p}_{3 / 2}$ spectra for electrochemically nitrided 2205 duplex stainless steel is shown in Fig. 1c. The peaks at $399.7 \mathrm{eV}$ and $396.8 \mathrm{eV}$ should be attributed to $\mathrm{NH}_{3}$ and nitrides [11], respectively. The binding energy value of $\mathrm{CrN}$ is ranging from 396.3 to $396.6 \mathrm{eV}$, while corresponding binding energy value of $\mathrm{Cr}_{2} \mathrm{~N}$ is ranging from 397.1 to $397.6 \mathrm{eV}$. Therefore, the surface nitrides should be mixture of $\mathrm{CrN}$ and $\mathrm{Cr}_{2} \mathrm{~N}$ based on the XPS results. The peaks at $393.4 \mathrm{eV}$ are attributed to Mo element. Obviously, surface nitriding is enhanced due to longer electrochemical nitridation time. Moreover, high amount of the wetting phase could facilitate the wetting of grain boundaries [12], which could also promote surface nitridation.

The potentiodynamic polarization curves of solid solution and electrochemically nitrided 2205 duplex stainless steels in borate buffer solution are shown in Fig. 2a. A steady current density in the potential region between $-0.17 \mathrm{~V}_{\mathrm{SCE}}$ and $0.2 \mathrm{~V}_{\mathrm{SCE}}$ is observed, which indicates that the surface of solid solution 2205 duplex stainless steel is in a primary passive state. It is evident that the anodic current decreases with the increasing of electrochemical nitridation time. In addition, all the samples exhibit similar breakdown potential in borate buffer solution. In Fig. 2b, the OCP of the stainless steel increases dramatically in the first $500 \mathrm{~s}$ and then reaches gradually to stable state. A longer electrochemical nitridation time results in a higher OCP value.

The Mott-Schottky analysis reveals negative and positive slopes in Fig. $3 a$, indicating $p$-type and $n$-type semiconducting character-
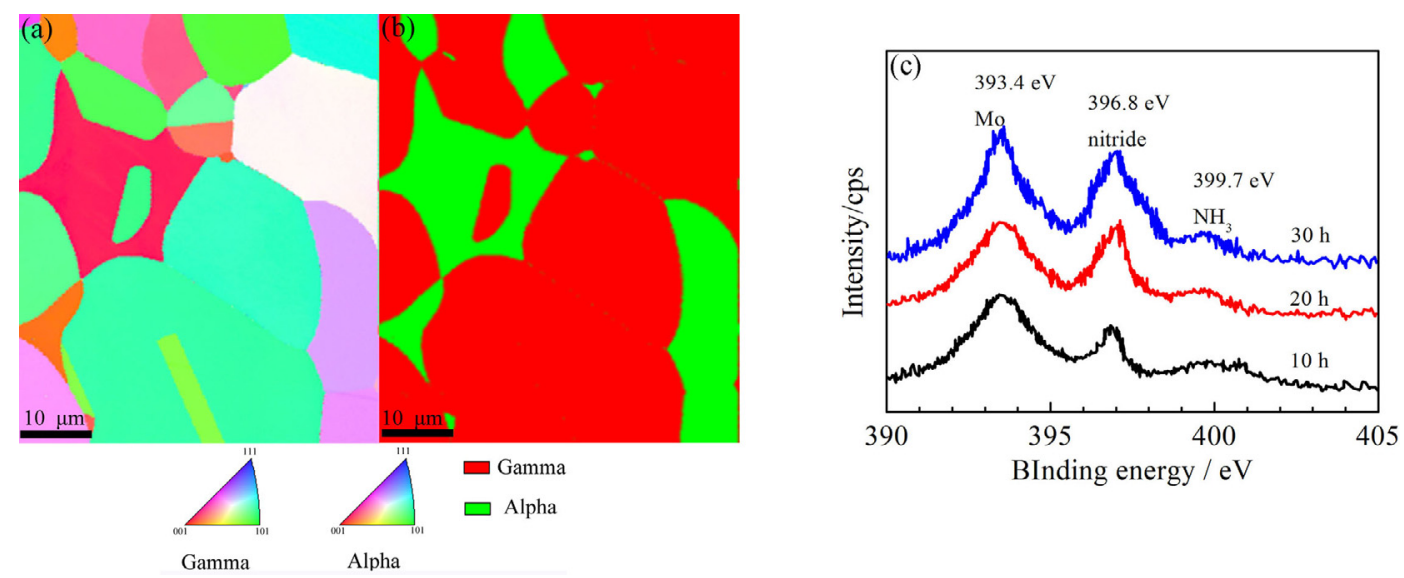

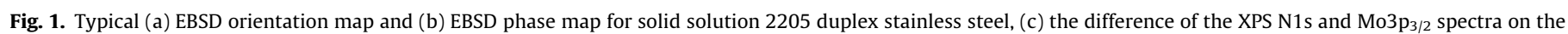
surface of three electrochemically nitrided 2205 duplex stainless steel.
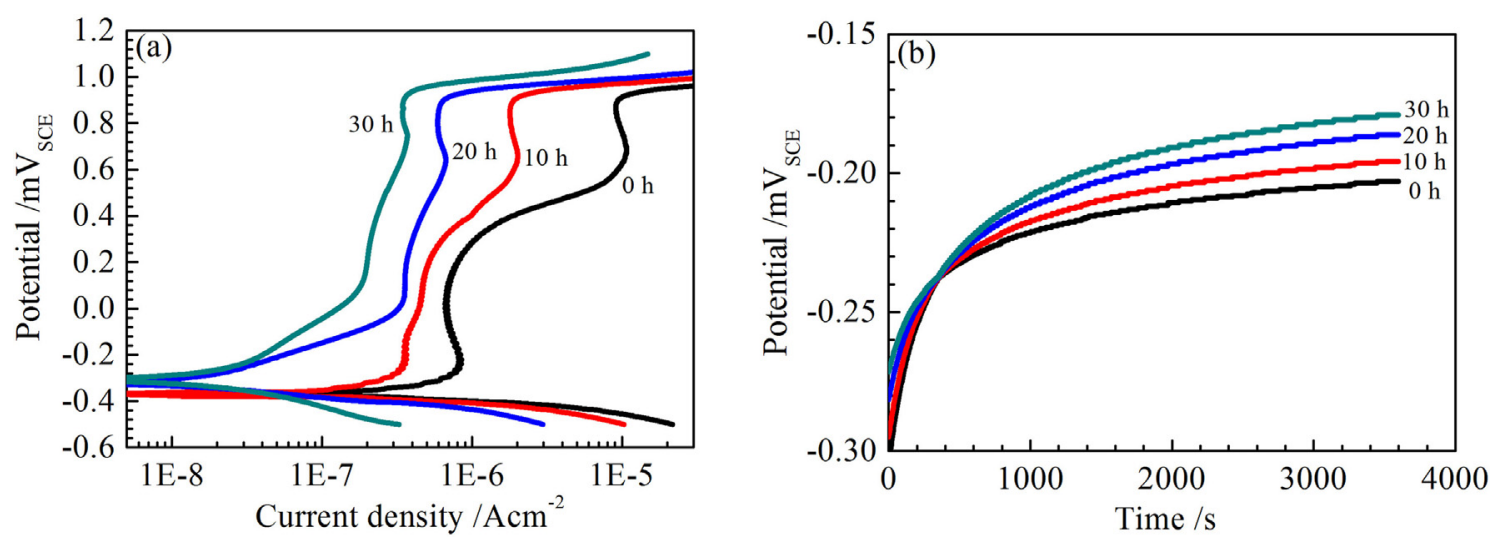

Fig. 2. (a) Potentiodynamic polarization curves and (b) the OCP in borate buffer solution for solid solution and electrochemically nitrided 2205 duplex stainless steels. 

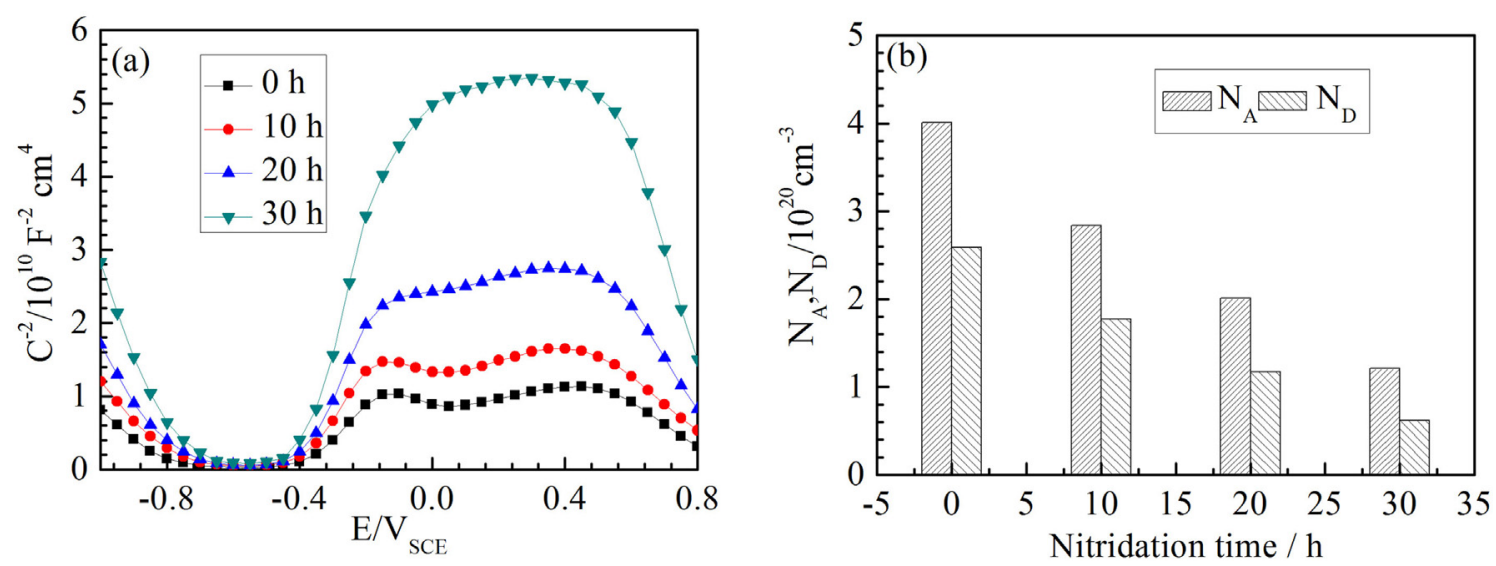

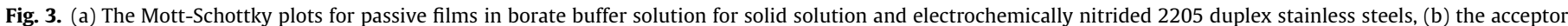
and donor concentrations in passive films.

istics irrespective of electrochemical nitridation time. It is worth noting that the non-linearity behavior above $-0.4 \mathrm{~V}_{\mathrm{SCE}}$ changes due to increased electrochemical nitridation time. It was demonstrated that the passive films should contain cation interstitials, oxygen vacancies (electron donors) or/both cation vacancies (electron acceptors) based on point defect model [13]. The non-linearity in Mott-Schottky curves could be attributed to the presence of two or more donor levels in the passive films, such as, oxygen vacancies and $\mathrm{Fe}^{2+}[14]$. Therefore, the Mott-Schottky analysis at present implies that electrochemical nitridation could also affect the formation and distribution of oxygen vacancies and cation interstitials in passive films. The acceptor concentration is always more than donor concentration in the passive films in Fig. 3b. Moreover, the doping concentration decreases with the increasing of electro- chemical nitridation time. Less doping concentration in passive films should improve significantly the corrosion resistance of electrochemically nitrided 2205 duplex stainless steel in borate buffer solution.

All the Nyquist plots show an unfinished semicircle arc in Fig. 4a. The semicircle radius of the 2205 duplex stainless steel increases with the increasing of electrochemical nitridation time. Moreover, one time constant also indicates compact passive film formed on the 2205 duplex stainless steel in borate buffer solution in Fig. 4b. The obtained charge transfer resistance values based on equivalent circuit in the insert are shown in Fig. 4c. The obtained results demonstrate that electrochemical nitridation treatment enhances the charge transfer resistance and thus improves the stability of the passive films.
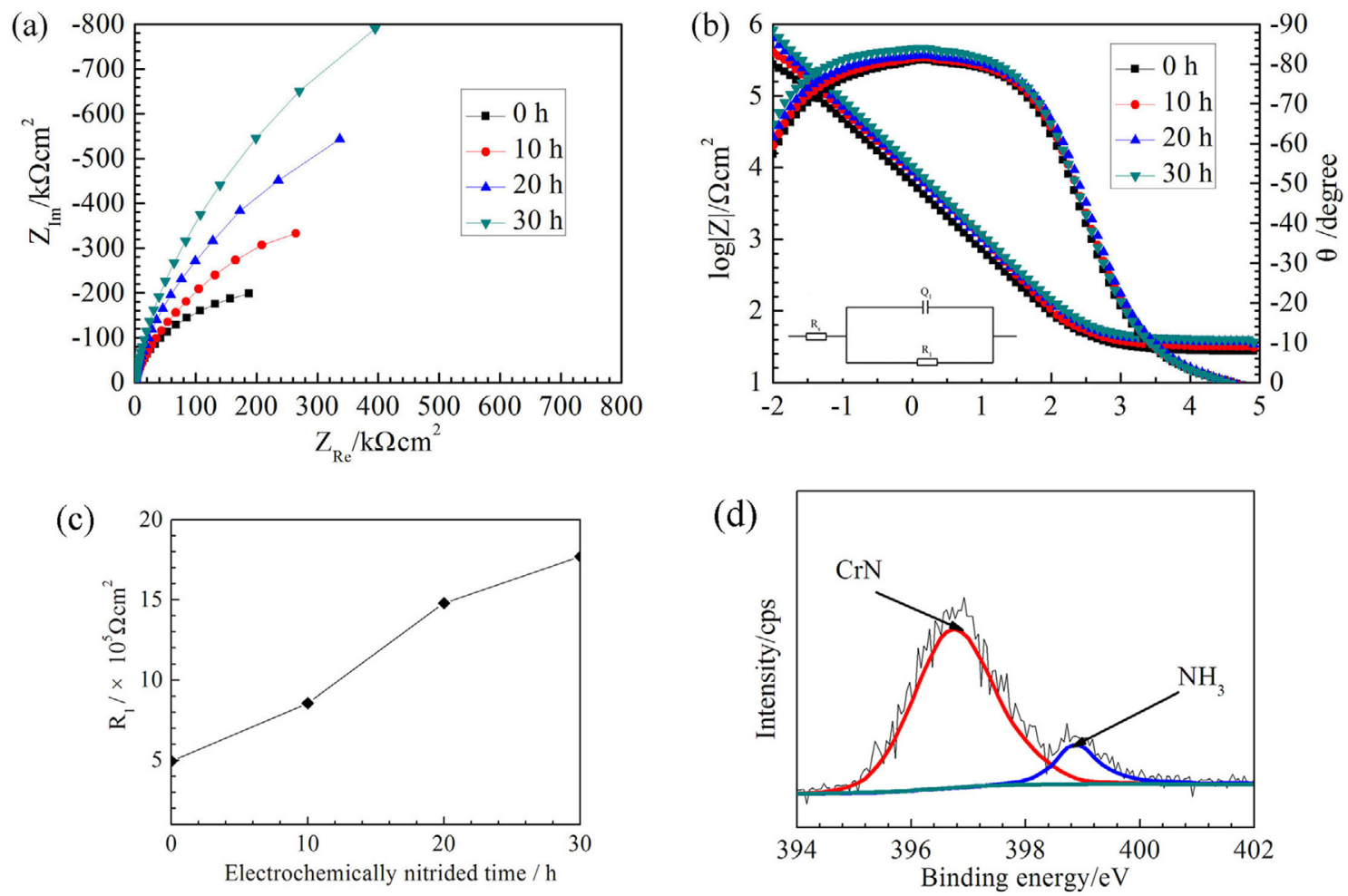

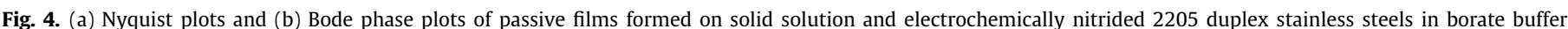

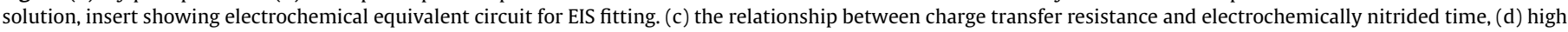
resolution XPS result of the passive film formed at $0.6 \mathrm{~V}_{\mathrm{SCE}}$ for $2 \mathrm{~h}$ in borate buffer solution for 2205 duplex stainless steel electrochemically nitrided for $30 \mathrm{~h}$. 
The present investigation shows that the electrochemical nitridation changes semiconductor characteristic of the passive films formed on the 2205 duplex stainless steel and reduces the doping concentration in the passive films. The corresponding spectrum of the passive film formed at $0.6 \mathrm{~V}_{\mathrm{SCE}}$ for $2 \mathrm{~h}$ in borate buffer solution for the 2205 duplex stainless steel electrochemically nitrided for $30 \mathrm{~h}$ can be curve-fitted with two dominant peaks for $\mathrm{CrN}$ (binding energy at $396.7 \mathrm{eV}$ ) and $\mathrm{NH}_{3}$ (binding energy at $398.8 \mathrm{eV}$ ) in Fig. 4c. This is consistent with previous reports [15]. It was found that there was an optimum nitrogen content for improving corrosion resistance of the martensitic stainless steel in chloride containing solution [16]. The high nitrogen content improved passive film stability, which could be attributed to the formation of ammonium ions [17] or nitrate/nitrite ions [18]. Because nitrate ions could effectively inhibit the anodic dissolution. Therefore, in the present study, although formation of chromium nitride could deteriorate the corrosion resistance of the 2205 duplex stainless steel due to reduced chromium content in passive film, high nitrogen content could also improve the stability of the passive film and decrease the donor and the acceptor concentrations in passive films. Stability and compact passive film could improve the corrosion resistance of electrochemically nitrided 2205 duplex stainless steel in borate buffer solution.

\section{Conclusions}

The present study investigated the effect of electrochemical nitridation on the corrosion resistance of the 2205 duplex stainless steel. Nitrogen enrichment was found on the surface of the 2205 duplex stainless steel by electrochemical nitridation treatment. The electrochemical nitridation affected semiconductor characteristics of the passive films on the surface of the 2205 duplex stainless steel. The electrochemically nitridation improved significantly the corrosion resistance of the 2205 duplex stainless steel in borate buffer solution due to decreased donor and acceptor concentrations in passive films. Although the reduced chromium content due to the forming of chromium nitride after electrochemically nitridation treatment could decrease the corrosion resistance of 2205 duplex stainless steel in borate buffer solution, stability and compact passive film improved the corrosion resistance of electrochemically nitrided 2205 duplex stainless steel.

\section{Declaration of Competing Interest}

The authors declare that they have no known competing financial interests or personal relationships that could have appeared to influence the work reported in this paper.

\section{Acknowledgement}

This work was financially supported by National Natural Science Foundation of China (Grant No. 91326203).

\section{References}

[1] Y. Fu, X.Q. Wu, E.H. Han, W. Ke, K. Yang, Z.H. Jiang, Effects of cold work and sensitization treatment on the corrosion resistance of high nitrogen stainless steel in chloride solutions, Electrochim. Acta 54 (2009) 1618-1629.

[2] H.Y. Ha, T.H. Lee, C.S. Oh, S.J. Kim, Effects of combined addition of carbon and nitrogen on pitting corrosion behavior of Fe-18Cr-10Mn alloys, Scr. Mater. 61 (2009) 121-124.

[3] D. López, N.A. Falleiros, A.P. Tschiptschin, Corrosion-erosion behaviour of austenitic and martensitic high nitrogen stainless steels, Wear 263 (2007) 347-354.

[4] J.B. Lee, S.I. Yoon, Effect of nitrogen alloying on the semiconducting properties of passive films and metastable pitting susceptibility of $316 \mathrm{~L}$ and $316 \mathrm{LN}$ stainless steels, Mater. Chem. Phys. 122 (2010) 194-199.

[5] P. Wan, Y.B. Ren, B.C. Zhang, K. Yang, Effect of nitrogen on biocorrosion behavior of high nitrogen nickel-free stainless steel in different simulated body fluids, Mater. Sci. Eng., C 32 (2012) 510-516.

[6] S. Ningshen, U.K. Mudali, V.K. Mittal, H.S. Khatak, Semiconducting and passive film properties of nitrogen-containing type 316LN stainless steels, Corros. Sci. 49 (2007) 481-496.

[7] C.X. Li, T. Bell, Corrosion properties of active screen plasma nitrided 316 austenitic stainless steel, Corros. Sci. 46 (2004) 1527-1547.

[8] A. Fossati, F. Borgioli, E. Galvanetto, T. Bacci, Corrosion resistance properties of glow-discharge nitrided AISI 316L austenitic stainless steel in $\mathrm{NaCl}$ solutions, Corros. Sci. 48 (2006) 1513-1527.

[9] P.R. Levey, A.V. Bennekom, A mechanistic study of the effects of nitrogen on the corrosion properties of stainless steels, Corrosion 51 (1995) 911-921.

[10] B.B. Straumal, Y.O. Kucheev, L.I. Efron, A.L. Petelin, J. Dutta Majumdar, I. Manna Complete and incomplete wetting of ferrite grain boundaries by austenite in the low-alloyed ferritic steel, JMEPEG 21 (2012) 667-670.

[11] G. Greczynski, D. Primetzhofer, J. Lu, L. Hultman, Core-level spectra and binding energies of transition metal nitrides by non-destructive $\mathrm{x}$-ray photoelectron spectroscopy through capping layers, Appl. Surf. Sci. 396 (2017) 347-358.

[12] I. Kaban, R. Nowak, O. Shuleshova, B. Korpala, G. Bruzda, A. Siewiorek, J.H. Han, N. Sobczak, N. Mattern, J. Eckert, Sessile drop study of Gd-Ti monotectic alloys on ceramic substrates: phase transformations, wetting, and reactivity, J. Mater. Sci. 47 (2012) 8381-8386.

[13] G.R. Engelhardt, B. Kursten, D.D. Macdonald, On the nature of the electric field within the barrier layer of a passive film, Electrochim. Acta 313 (2019) 367377.

[14] S. Modiano, C.S. Fugivara, A.V. Benedetti, Effect of citrate ions on the electrochemical behaviour of low-carbon steel in borate buffer solutions, Corros. Sci. 46 (2004) 529-545.

[15] S. Ramya, T. Anita, H. Shaikh, R.K. Dayal, Laser Raman microscopic studies of passive films formed on type $316 \mathrm{LN}$ stainless steels during pitting in chloride solution, Corros. Sci. 52 (2010) 2114-2121.

[16] X. Qi, H.H. Mao, Y.T. Yang, Corrosion behavior of nitrogen alloyed martensitic stainless steel in chloride containing solutions, Corros. Sci. 120 (2017) 90-98.

[17] R.F.A. Jargelius-Petterson, Sensitization behaviour and corrosion resistance of austenitic stainless steels alloyed with nitrogen and manganese, ISIJ Int. 36 (1996) 818-824.

[18] R.C. Newman, M.A.A. Ajjawi, A micro-electrode study of the nitrate effect on pitting of stainless steels, Corros. Sci. 26 (1986) 1057-1063. 